\section{Representación, lenguaje y realidad: acerca de las posibilidades de la historia reciente}

Representation, language and reality: about the possibilities of recent history

\section{Camila Cárdenas Neira **}

\section{Resumen}

Este artículo presenta una discusión bibliográfica que recoge planteamientos de la historia, los estudios del discurso, la comunicación y la semiótica social, a fin de proponer algunos aspectos críticos y la manera en que éstos intervienen en la representación de la realidad social como discurso histórico. En particular, si dicha realidad recoge acontecimientos recientes cuyas versiones aún resultan contradictorias y

El artículo es parte de la tesis de la autora vinculada al Proyecto Fondecyt № 1090464 "Logogénesis valorativa en el discurso de la historia", realizada gracias al financiamiento otorgado por el Programa de Formación de Capital Humano Avanzado, Becas de Magíster Nacional 2010 de la Comisión Nacional de Investigación Científica y Tecnológica (CONICYT).

** Centro de Idiomas, Facultad de Filosofía y Humanidades, Universidad Austral de Chile. Isla Teja s/n, Valdivia. E-mail: camila. cardenas.neira@gmail.com. pugnan por legitimación, como es el caso de las experiencias dictatoriales latinoamericanas ocurridas durante las últimas décadas. En este marco, se busca dar respuesta a interrogantes tales como: ¿qué rol le cabe al lenguaje en la construcción de discursos que pretenden lectores alineados ideológicamente a ciertas representaciones históricas?, ¿qué factores determinan que una versión se establezca como única realidad admisible para la comprensión de sucesos históricos recientes?, ¿qué efectos trae para la memoria compartida que ciertos grupos sociales ostenten mayor autoridad que otros para fijar el sentido de la experiencia colectiva?, ¿cómo se mantienen o transforman las memorias hegemónicas?, ¿qué ocurre cuando dichos sentidos se desprenden de hechos históricos traumáticos? A continuación, se organizan cinco ejes expositivos a fin de proveer algunos sentidos posibles a las respuestas que se persiguen, las cuales concluyen en el papel que le cabe a la enseñanza del lenguaje en la recuperación de la historia reciente, así como los aportes que una pedagogía crítica ofrece a la reconstrucción de la memoria ciudadana.

Palabras clave: realidad social, lenguaje, discurso histórico, pasado reciente.

\section{Abstract}

This article presents a bibliographic review which takes analysis from history, discourse studies, communication and social semiotic in order to establish some critical aspects related to how these take part in the representation of the social reality as a historical discourse. Specifically, the aim is to analyze if the reality presented involves some recent events which 
narration still result contradictory and struggling by legitimization, as it happens with the LatinAmerican dictatorships from the last decades. Through the previous frame the target is to answer questions such as: What is the role of language in the discourse construction pretended by ideologically lined up readers towards some historical representations? What are the factors which determine a narration as the only accepted reality in the comprehension of recent historical events? What are the effects in the collective memory the fact that some social groups perform a higher validation than others when establishing the interpretation of the collective experience? How are the hegemonic memories maintained or transformed? What happens when these interpretations result from traumatic historical events? Consequently, five cores of theoretical discussion are introduced in order to provide some hints for the questions presented, these will lead to the role of language teaching in the recovery of recent history, as well as the contribution of a critical pedagogy in the reconstruction of people's memory.

Key words: social reality, language, historical discourse, recent past.

\section{Introducción}

Este artículo constituye una revisión teórica interdisciplinaria que busca establecer elementos críticos que inciden en la construcción de cierta realidad social como discurso histórico. Especialmente, se concentra en aspectos que resultan decisivos en una lectura de la historia reciente, sobre todo si ésta se encuentra atravesada por acontecimientos traumáticos derivados de guerras civiles o experiencias dictatoriales, como es el caso de muchos países latinoamericanos. De esta manera, se relevan cuatro ejes de discusión y uno de síntesis, que buscan esclarecer:

a) El rol que le cabe al uso del lenguaje en la construcción de la realidad social;

b) Los factores derivados de este uso que intervienen en la conformación del conocimiento histórico;

c) Los aspectos lingüísticos, psico-sociales e ideológicos que se ponen en juego para la selección, configuración y tratamiento de las narrativas históricas;

d) El papel que desempeñan la memoria y el olvido en la conformación de narrativas hegemónicas y contrahegemónicas, y;

e) La importancia de una pedagogía crítica que posicione los elementos descritos en la transmisión -reproducción o transformacióndel pasado reciente, sobre todo si éste reviste un cariz traumático no resuelto.

La principal característica de una revisión de esta naturalezaesque sitúaunhorizonteinterpretativo de carácter comunicativo, es decir, reconoce la práctica historiográfica a partir de diversas interacciones propiciadas por los usuarios del lenguaje, siendo éstos, con sus respectivas creencias, contextos de producción y recepción discursiva, acciones políticas, nichos de poder, entre otros, quienes definen la profundidad y alcance de determinadas experiencias sociales. Es así como ciertos hechos, a la luz de la intencionalidad historiadora, se traducen -0 no- en conocimiento histórico legitimado y, por tanto, comunicable a las generaciones futuras. Justamente, cuando dichos conocimientos 
emergen de episodios traumáticos recientes, obligan una lectura ya no circunscrita a los pormenores de la discusión teórica, sino a la comprensión de ciudadanos comunes que aprehenden la historia -rememoran, silencian u olvidan-, en virtud de resignificaciones mediadas por distintas instancias de educación formal o informal, pública o privada.

\section{Sobre el uso del lenguaje y la construcción de la realidad social}

La realidad social se constituye de forma multivariada, es decir, mediando una serie de factores cognitivos, sociales y lingüísticos. Como punto de partida, Potter (1998) aclara que la realidad -0 la idea de realidad que definimos en tanto sujetos-, se introduce en las prácticas humanas por medio de las categorías y las descripciones que forman parte de esas prácticas, por lo que uno de los temas principales de su propuesta es cómo se organizan tales descripciones para hacer que una versión parezca creíble y objetiva para ser comprendida como experiencia compartida. A propósito de los criterios de validez con que ha de llevarse a cabo dicha configuración, Habermas (2001) propone las siguientes distinciones: inteligibilidad, veracidad, verdad y rectitud. El concepto que gravita en su propuesta es el de 'pretensión'; los hablantes deben seguir una serie de parámetros comunicativos coherentes. Cabruja, Íñiguez y Vásquez (2000) señalan, en este marco, que el punto de partida para la comprensión de la realidad social es la consideración de ésta como una construcción erigida sobre la base de significados. En relación a ello, los autores promueven el análisis de los siguientes aspectos:
-La relevancia de la vida cotidiana y la participación simultánea de las personas en diferentes espacios de relación.

-La intersubjetividad: los significados se crean en o provienen de las relaciones. Es decir, las personas actuamos en función de otras, con relación a contextos, significados y producciones sociales (instituciones, costumbres, discursos, prácticas, etc.).

-La indexicalidad: un mismo fenómeno cambia de sentido en diferentes situaciones.

-La reflexividad: es en la propia relación entre las personas cuando se crea la situación, y es la situación creada la fuente y el tema que propicia la relación.

-Los escenarios y las acciones humanas: éstas sólo tienen sentido en marcos sociales, y son estos marcos los que permiten entender los cambios de sentido y/o las elaboraciones y reelaboraciones de significados.

-El carácter político de la acción social: ésta es inseparable de la producción de efectos, de las relaciones de poder y de su dimensión ética (2000: 64).

En virtud de estas consideraciones queda de relieve el vínculo indisociable entre lenguaje y sociedad. Usar el lenguaje implica generar una serie de prácticas situadas cultural y situacionalmente, mediante las cuales no sólo representamos el mundo sino que lo cocreamos a partir de la palabra. Potter (1998), a su vez, consigna que siempre que se expresan palabras se construyen hechos. Al utilizarse el lenguaje descriptivo se producen múltiples versiones que pugnan por posicionarse como verdades incuestionables. Sin embargo, conviene preguntarse de acuerdo a este autor, qué determina que algunas versiones funcionen y otras no, es decir, "por qué una versión se trata como una representación factual de cómo 
son las cosas en una interacción, o por qué se rechaza considerándola sesgada, confusa o interesada" (1998: 135). En este sentido, Potter advierte que las descripciones suelen asociarse con la frialdad, la objetividad y la neutralidad, especialmente en contextos donde tales características son institucionalmente reforzadas. De acuerdo a este autor, es precisamente este aspecto lo que hace que "las versiones factuales sean tan convenientes cuando existe un conflicto o una cuestión de cariz delicado" (1998: 144).

En este sentido, la discusión en torno a la construcción del pasado reciente como discurso histórico constituye un punto de inflexión, pues, no hay consenso respecto de los márgenes temporales que distinguen el límite entre aquello que aconteció y aún está sucediendo. Para la lingüista y analista del discurso, Mariana Achugar, esta imprecisión es la que colabora, justamente, en poner en relación los distintos argumentos: "el pasado reciente investiga temas que vinculan pasado y presente, en particular aquellos en los que la memoria social está viva y todavía existen actores sociales que pueden testimoniarlo" (2011: 45). Es así como encontramos un contexto en que historia y memoria coinciden, es decir, en donde el estatus epistemológico de la historia se resuelve dentro de las comunidades interpretativas. De allí que la construcción de dicha memoria requiera de una comprensión histórica compartida, sobre todo en casos donde no se logra consenso acerca de cómo recordar el pasado y existen versiones contradictorias de éste. Por esta razón, el control sobre la memoria se convierte en una arena de debate político cuya función es, de acuerdo a esta autora, 'filtrar' el pasado en los espacios públicos y privados. Dados estos alcances, Achugar propone un abordaje interdisciplinario del tema: "el estudio del pasado reciente no es monopolio de los historiadores, sino que le compete a muchos campos de investigación" (2011: 44). Específicamente, esta autora se interesa por las prácticas discursivas que intervienen en su transmisión, perspectiva que resulta complementaria a la entregada por los estudios históricos. Este acercamiento vincula estrechamente el rol del lenguaje a la constitución de la realidad histórica:

\begin{abstract}
En efecto, para hacer inteligible la realidad, los seres humanos necesitamos recurrir a una narración de la misma, pero son a su vez las narraciones y narrativas que se entrecruzan y dialogan entre ellas las que otorgan realidad al mundo en el que vivimos. Cuando nacemos lo hacemos en un mundo ya construido. Esto significa que el lenguaje nos incorpora y nos vamos incorporando al lenguaje mediante la adopción compartida de conceptos y categorías que nos permiten explicar el mundo. Son estos conceptos y categorías que preexisten los que nos permiten ir "asimilando" y dando cuenta de la realidad. Mediante nuestras relaciones y prácticas accedemos a un mundo construido, pero, simultáneamente, contribuimos a su construcción (Cabruja, Íñiguez y Vásquez 2000: 65).
\end{abstract}

Estos autores añaden que analizar las formas mediante las cuales construimos experiencia social, implica considerar cómo se lleva a cabo dicha construcción justamente desde discursos y prácticas sociales que ocupan un lugar de enunciación privilegiado: "por lo tanto, no es representar mundo y hechos sino sustentar ciertas modalidades de orden social lo que caracteriza a las narraciones que utilizamos (...) El respeto de estos criterios, es decir, su reproducción, constituye, simultáneamente, la reproducción del orden social" (2000: 69, cursiva mía). Achugar (2011), por su parte, destaca esta conexión específicamente en lo que respecta a casos de relevancia política. 
La vinculación entre la producción discursiva y el orden socio-político constituye, entonces, un elemento clave. La actividad simbolizante surge a partir de las experiencias enunciadas de modo tal que la representación resultante es, en efecto, una re-presentación de las mismas. Dicha representación se produce de manera iterada sin que implique, necesariamente, repetición. Este sentido de 'volver a mostrar' la realidad involucra, la mayoría de las veces, modificación. En tal modificación se ponen en juego las motivaciones, intenciones, intereses y propósitos comunicativos de los enunciantes, por lo que, en ningún caso, constituyen una copia idéntica de la realidad enunciada. Distintos modos de representación funcionan como un correlato de las prácticas sociales, y tienen el potencial de informar acerca de sus estructuras, jerarquías y formas de funcionamiento. En este punto, los enunciados insertos en situaciones de uso particulares, actúan en distintas direcciones ya sea regulando o interviniendo sobre contextos socioculturales específicos.

Existe una preocupación concreta desde distintas perspectivas teóricas por analizar los modos de producción discursiva y los procedimientos específicos que regulan su comprensión. Precisamente, ciertas formas de discurso público (van Dijk 2009), y en particular, textos pertenecientes a géneros académicos y especializados, cuentan con un acceso que es mayormente controlado. De acuerdo a Cabruja, Íñiguez y Vásquez (2000), los discursos históricos constituyen un caso ejemplar de la manera en que se construye objetividad:

Así, por ejemplo, la memoria como práctica social de construcción del pasado colectivo o personal, como acción conjunta, como argumentación, etc., tiene sus funciones y actúa en el presente: condiciona estrategias, abre espacios para compartir, genera contextos de expresión y comunicación, permite justificaciones, mantiene determinados órdenes sociales, genera sentimientos compartidos, produce valoraciones morales y éticas $y$, en definitiva, proporciona las bases de una acción futura y de su legitimación (...) En otras palabras, las narraciones, con toda su diversidad, funcionan como formas de poder y de control en las distintas situaciones o contextos de comunicación (2000: 70-71).

En este sentido, la pretensión de veracidad y validez con que operan estos discursos dificulta su aprehensión dado que los destinatarios no cuentan con los referentes empíricos para lograr una versión alternativa de los hechos. De acuerdo al estudioso del discurso Teun van Dijk (1999), mientras más desprovisto esté el lector de representaciones anteriores, más susceptible se encuentra para construir visiones estereotipadas y manipuladas. De allí que sea necesario centrar la mirada en los modos en que se elaboran dichas representaciones en torno a actores, procesos y circunstancias históricas, a fin de lograr un acceso más igualitario y democrático. Según Achugar (2011), esto requiere de una mediación entre la experiencia y el discurso que representa, orienta y organiza los significados, toda vez que el conocimiento histórico necesita ser valorado y validado por la comunidad de referencia.

\section{Sobre la construcción del conocimiento histórico}

En lo que respecta a la realidad que se historiza, el conocimiento histórico se construye sobre la base del pasado; ésa es la primera distinción que nos ocupa. Comprender qué es, efectivamente, ese pasado, implica atender que "La operación historiográfica procede de una 
doble reducción: la de la experiencia viva de la memoria y la de la especulación multimilenaria sobre el orden del tiempo" (Ricoeur 2010: 208). Ahora bien, tanto esta idea del tiempo, como la del espacio en que éste sobreviene, se constituyen, de acuerdo a la historiadora Elizabeth Jelin (2001), como construcciones sociales: "si bien todo proceso de construcción de memorias se inscribe en una representación del tiempo y del espacio, estas representaciones $-y$, en consecuencia, la propia noción de qué es pasado y qué es presente- son culturalmente variables e históricamente construidas" (2001: 23). Asimismo, el sociólogo Norbert Lechner (2006) propone una distinción similar respecto de las nociones de memoria y olvido, ambas son construcciones continuamente elaboradas y reformuladas: "Como parte de ese proceso de producción, la memoria y el olvido, el presente y el futuro actúan y se ordenan como simbolizaciones de esa gran obra de la acción colectiva que llamamos historia" (2006: 525).

Una primera distinción notable nos lleva a considerar el carácter construido de la historia, que sólo aprehendemos en la forma de un conocimiento específico. El marco de este conocimiento es fundamentalmente sociocultural. De acuerdo a Paul Ricoeur, "los modelos explicativos aplicados en la práctica historiadora poseen como rasgo común el referirse a la realidad humana como hecho social. En este sentido, la historia social no es un sector entre otros, sino el punto de vista desde el cual la historia escoge su campo, el de las ciencias sociales" (2010: 237-238). Por lo tanto, el principal referente del discurso histórico son las interacciones capaces de crear un vínculo social entre los sujetos involucrados. En así como pensar en la historia y las prácticas simbólicas que la vuelven aprehensible, demanda complejizar la visión unívoca en virtud de la cual la historia se erige como un 'reflejo de lo que verdaderamente aconteció': ¿cómo, por qué, según quién?

La discusión anterior sobre la construcción social de la realidad cobra aquí un cariz renovado. De acuerdo a Ricoeur (2010), la historia se hace posible mediante la operación de traer al presente un pasado ausente, no obstante, ese tránsito implica re-presentación. Para Achugar (2011) la construcción del pasado es hecha desde el presente y es motivada por objetos presentes con miras al futuro. En este sentido, el pasado no es una entidad discreta, autónoma y semánticamente acotada, no se recupera únicamente a partir de un proceso cognitivo. Traer de vuelta el pasado involucra un (re)hacer, se trata de un ejercicio individual y colectivo que a la vez que actúa, transforma; sugiere, por tanto, pensar más bien en una pragmática de la memoria (Ricoeur 2010). A la visión de una historia homogénea, estable y verdadera, sumo la necesidad de una reflexión que, según Lechner (2006), se dirija hacia la 'naturalización de lo social', entendida como la transfiguración del orden social en un orden natural aparente. De acuerdo a este autor, Este proceso crea no sólo la distinción por todos
conocida entre la naturaleza y el ámbito de la
acción social. Además, termina por asimilar la
sociedad a la naturaleza. La antigua idea de un
orden social, evaluado según normas morales,
es sustituida por la concepción de un sistema
abstracto e impersonal. Lo social es concebido
como una estructura objetiva que sería la premisa
(no necesariamente consciente) de la acción
humana. Se consolida así la escisión entre objeto
y sujeto, entre estructura y acción, entre sistema
y mundos de vida. La consecuencia es de gran
alcance: la subjetividad de las personas, sus
valores y emociones, son expulsadas de la reflexión 
científica. La investigación social es puesta bajo el imperativo metodológico de un acto neutral en relación a los valores. En resumidas cuentas, tiene lugar una objetivación de lo social a la vez que una des-subjetivación de la reflexión (2006: 484).

En este sentido, la naturalización del proceso social que garantiza un orden seguro e intocable, es articulada con facilidad a la idea de una historia como entidad disociada y absoluta. La necesidad de estabilizar una realidad que parece inasible en su transformación continua, opera entonces como fundamento para la interacción social. Por consiguiente, fijar un orden 'como si' fuese inamovible y auto-regulado, facilita a las personas desarrollar relaciones uniformes y previsibles entre sí.

A la luz de estos planteamientos queda de manifiesto que cualquier teoría de la sociedad es una construcción cultural, en tanto funcionan como representaciones simbólicas de la misma. Estas teorías -incluida entre ellas la historiografía-, tienen la capacidad de atribuir significados a los diversos aspectos de la vida social. Por esta razón, se hace prioritario volver la mirada hacia las representaciones simbólicas mediante las cuales hacemos inteligible la realidad social. En palabras de Lechner, "/o social es indisociable de su representación. Ninguna situación es inteligible sin esquemas de interpretación que den sentido y coherencia a la multiplicidad y complejidad de los elementos en juego" (2006: 492, cursiva mía).

En lo que respecta al campo de la historia, Ricoeur se plantea la necesidad de saber en qué condiciones esta representación es, en efecto, una reproducción del pasado. La primera distinción que este autor establece es de orden fenomenológico: "De la respuesta a esta cuestión depende la diferencia entre imaginación y recuerdo" (2010: 57). De esta manera, se establece que, mientras que la imaginación puede actuar con entidades de ficción, el recuerdo sólo presenta las cosas que realmente han ocurrido en el pasado, de modo tal que lo ficcional y lo fingido quedan fuera de dicha representación. En esta línea, la representación histórica está necesariamente asociada a una rememoración que trae al presente algo ya dado en el pasado;

\begin{abstract}
se puede afirmar que una exigencia específica de verdad está implicada en el objeto de la 'cosa' pasada, del qué anteriormente visto, oído, experimentado, aprendido. Esta exigencia de verdad especifica la memoria como magnitud cognitiva. Más precisamente, es en el momento del reconocimiento, con el que concluye el esfuerzo de la rememoración, cuando se declara esta exigencia de verdad. Entonces sentimos y sabemos que algo sucedió, que algo tuvo lugar, que nos implicó como agentes, como pacientes, como testigos. Llamemos fidelidad a esta exigencia de verdad. Hablaremos en lo sucesivo de la verdad-fidelidad del recuerdo para explicar esta exigencia (2010: 79).
\end{abstract}

En un sentido más general, Ricoeur sostiene que "el historiador intenta representarse el pasado de la misma manera en que los agentes sociales se representan el vínculo social y su contribución a este vínculo, haciéndose así implícitamente lectores de su ser y de su actuar en sociedad y, en este sentido, de su tiempo presente" (2010: 304, cursiva mía). Lo que destaca de este planteamiento es la capacidad de los sujetos sociales de 'encontrarse' en la esfera social mediante la aprehensión de las representaciones a las que acceden. Asimismo, Achugar (2011) introduce la noción de conciencia histórica cuando se cuestiona ¿cómo los individuos y los grupos construyen la relación entre el espacio y el tiempo, a la vez que se posicionan en este marco para definir su 
identidad como miembros de un grupo social? De esta manera, dicha conciencia funciona como modo de orientación en situaciones de la vida presente, que implica tener una interpretación histórica que explica la situación actual en relación a una matriz temporal. De allí que la discusión tienda hacia los aspectos que intervienen en la construcción de tales representaciones.

En cuanto al uso propiamente tal de este término, Ricoeur distingue al menos dos delimitaciones semánticas: la representaciónobjeto y la representación-operación. La primera hace alusión a la entidad histórica representada, mientras que la segunda refiere el proceso por medio del cual se configura dicha representación. Para Ricoeur, la representaciónobjeto "funciona en el plano de la formación de vínculos sociales y de las identidades sociales, en la medida en que la forma en que los agentes sociales se comprenden está en relación con la forma con que los historiadores se representan esta conexión entre representación-objeto y acción social" (2010: 308). La representaciónoperación, en cambio, se observa a partir de "la dialéctica entre la referencia a la ausencia y la visibilidad de la presencia perceptible en la representación-objeto (...) Esto devela el vínculo profundo que existe entre memoria e historia (...) A la representación mnemónica sigue, en nuestro discurso, la representación histórica (2010: 308)". En virtud de lo expuesto, Ricoeur enfatiza que la representación en el plano histórico no se limita a conferir un 'ropaje verbal' al discurso -en cuanto requiere del lenguaje para su expresión-, sino que constituye "una operación de pleno derecho que tiene el privilegio de hacer emerger el objetivo referencial del discurso histórico" (2010: 309). En esta dirección, Achugar plantea desde el ámbito de los estudios del discurso que "el significado del texto no se encuentra en el texto mismo sino en los procesos que establecen complejas relaciones semióticas entre discursos y autores/lectores" (2011: 47, cursiva mía).

A esta operación subyace el término que Ricoeur consigna como 'representancia', cuya característica principal es aglutinar todas las expectativas y exigencias vinculadas a la intencionalidad historiadora. Representancia designa, por tanto, "la espera vinculada al conocimiento histórico de las construcciones que constituyen reconstrucciones del curso pasado de los acontecimientos" (2010: 361). Esta conexión entre conocimiento histórico y representaciones adquiere en este punto especial relevancia. Sobre todo, porque recalca la impronta psico-social con que se aprehende la historia a partir de las representaciones que se negocian en el discurso.

\begin{abstract}
El significado de [la] historia está también en su objetivo [el del historiador]. Su exactitud empírica como definida y verificada en el contexto específico es necesaria a la producción histórica. Pero la exactitud empírica por sí sola no es suficiente. Representaciones históricas -como sus libros, exhibiciones comerciales o conmemoraciones públicas- no pueden ser concebidas sólo como vehículos para la transmisión de conocimiento. Ellos deben establecer alguna relación con ese conocimiento, no sea que las representaciones se hagan una falsificación, un espectáculo moralmente repugnante (Trouillot 1995: 149, cursiva mía). ${ }^{1}$
\end{abstract}

En efecto, la construcción del conocimiento histórico es indisociable de la capacidad de los agentes que configuran sus representaciones y determinan su alcance. Por lo tanto, el

En lo sucesivo las citas de textos originales en inglés corresponden a traducciones de elaboración propia. 
vínculo que los historiadores establecen con el conocimiento construido se torna fundamental. En esta línea, Elizabeth Jelin añade que "los conocimientos no son piezas sueltas que se pueden apilar o sumar, sino que sólo tienen sentido en marcos interpretativos socialmente compartidos" (2001: 127). De esta manera, se refuerza el carácter socioculturalmente situado de la práctica historiográfica. En palabras de Peter Burke,

\begin{abstract}
El relativismo cultural se aplica, como es obvio, tanto a la historiografía misma como a lo que se denomina sus objetos. Nuestras mentes no reflejan la realidad de manera directa. Percibimos el mundo sólo a través de una red de convenciones, esquemas y estereotipos, red que varía de una cultura a otra. En tal situación, nuestra comprensión de los conflictos se ve aumentada por la presentación de puntos de vista opuestos, más que por el intento de expresar un acuerdo (2003: 20).
\end{abstract}

La visión que subyace a estas ideas deviene de una forma particular de comprender la cultura. A este respecto atiendo la postura de luri Lotman (1998), quien establece que la cultura es un sistema de signos en cuyo interior existe un "dispositivo estereotipizador" que se articula por medio del lenguaje. En este sentido, los rasgos característicos de una cultura se condicen con los diferentes aspectos de la esencia sígnica que la constituye. Éstos deben ser vistos a partir de su historicidad y del modo en que modelan el comportamiento humano. Según este autor, la labor de la cultura consiste en organizar estructuralmente el mundo que rodea a las personas, y pone de relieve su capacidad de crear alrededor del hombre una socioesfera -una semiósfera-, que hace posible la vida en términos relacionales. A partir de este planteamiento, Lotman (1998) deja de manifiesto el problema del sistema de reglas semióticas según las cuales la experiencia de la vida humana se convierte en cultura. Así se evidencia la emergencia de un programa que traduce la experiencia inmediata en texto, por medio de la lengua como mecanismo memorizante. De allí que el conocimiento histórico pueda configurarse y fijarse culturalmente por medio del lenguaje.

A través de la lengua, la cultura crea textos en donde se establecen los sentidos que son funcionales dentro de una sociedad. Según Burke (1996), comunicarse constituye una forma de hacer en que "la lengua es una fuerza activa dentro de la sociedad, un medio que tienen los individuos y grupos para controlar a los demás o para resistir a tal control, un medio para modificar la sociedad o para impedir el cambio, un medio para afirmar o suprimir identidades culturales" (1996: 38). Asimismo, Lotman (1998) agrega que la historia de la marginación de los textos, de su exclusión de las reservas de la memoria colectiva, se mueve paralelamente a la creación de otros textos. En este sentido, la elección de los modos de representación histórica que se realiza sobre la base de unos u otros modos semióticos, da cuenta, necesariamente, de las prácticas modeladoras que influyen en la constitución de la sociedad.

Lo que opera en este ejercicio es el enfrentamiento histórico de los grupos por legitimarse en el entramado social. Para Antonio Gramsci, el concepto de hegemonía devela "la situación de una clase que alcanza una sólida unidad de ideología y de política, que le permite establecer una ascendencia sobre otros grupos y clases sociales" (1968: 20). Con este propósito, los sujetos se valen de distintas formas para moldear el "espíritu 
público", es decir, transformar sus concepciones en sentido común, y asegurar el consenso de las masas dentro del orden existente. Esta hegemonía puede expresarse política, estatal y culturalmente. En este último plano, se sirve de una serie de aparatos (producción histórica, educativa, periodística, literaria, entre otras), a fin de lograr: "1) el consentimiento 'espontáneo' de las grandes masas de la población a la dirección impresa a la vida social por el grupo fundamentalmente dominante $(\ldots), 2$ ) un aparato de coerción estatal que asegura 'legalmente' la disciplina de aquellos grupos que no 'consienten' ni activa ni pasivamente" (1968: 35). Para este autor, construir un edificio cultural completo, autárquico, implica reconocer la lengua como medio de expresión y contacto recíproco. Por ello es tan importante el papel que le cabe al lenguaje en la reconstrucción de la narrativa histórica, cuya configuración muestra "la coherencia y clausura de una serie de acontecimientos cuando existe un sujeto social que exige legitimación" (White 2003: 27).

Así también, van Dijk (2009) da cuenta de cómo la forma en que se utiliza el lenguaje es decisiva para la expansión ideológica y el consenso entre sus participantes, toda vez que las ideologías controlan la elaboración de representaciones sociales que permean la estructura del conocimiento, influyen en su adquisición y orientan las actitudes que los grupos comparten acerca de ciertas cuestiones sociales que modelan sus prácticas y su identidad. En lo que respecta específicamente a la transmisión del pasado reciente, Achugar (2011) recalca que las narrativas colectivas sobre el pasado son un tipo de conocimiento textualmente mediado y socialmente distribuido, sobre el cual se toman decisiones a nivel de qué pasó y de qué significa aquello que aconteció. De allí que el discurso, su manipulación y el control que ciertos grupos sociales ejercen en torno a su acceso, tiene un papel central en la construcción, explicación y comprensión de la historia reciente. En términos similares, Jelin agrega:

Partiendo del lenguaje, entonces, encontramos una situación de luchas por las representaciones del pasado, centradas en la lucha por el poder, por la legitimidad y el reconocimiento. Estas luchas implican, por parte de los diversos actores, estrategias para 'oficializar' o 'institucionalizar' una (su) narrativa del pasado. Lograr posiciones de autoridad, o lograr que quienes las ocupan acepten y hagan propia la narrativa que se intenta difundir, es parte de estas luchas. También implica una estrategia para 'ganar adeptos', ampliar el círculo que acepta y legitima una narrativa, que la incorpora como propia, identificándose con ella (2001: 36).

\section{Sobre la historia como narrativa}

Deestamanera, la luchapor las representaciones del pasado se vincula íntimamente a las formas de hacer historia que otorgan un particular estatuto a esta pugna. En efecto, el modo en que se concibe la práctica historiográfica determina, en gran medida, la configuración de sentido que productores y usuarios llevan a cabo a partir de la aprehensión de sus discursos. A grandes rasgos, se establece una discusión que sitúa, de un lado y otro, a quienes privilegian una comprensión de la historia como verdad o como construcción narrativa. Por una parte, la historia se erige como una explicación causal de los hechos 'tal como ocurrieron', mientras que, por otra, la historia se constituye mediante la configuración de una narración como modo explicativo alternativo a uno homogéneo e impuesto. La historia-problema se enfrenta a la historia-reflejo, pero, según Ricoeur, "para unos y otros, narrar equivale a explicar" (2010: 309). 
Esta operación, en cuanto requiere de una actividad simbolizante que la haga posible, resulta indisociable de la intencionalidad humana asociada a cualquier expresión socialmente mediada. Es, precisamente, un cierto modo de entender el lenguaje, ya como espejo, ya como acción, lo que enmarca el debate en torno a la naturaleza del conocimiento histórico. En esta línea, Ricoeur (2010) sostiene que la disputa por el carácter narrativo de los discursos históricos tiene, en efecto, un origen lingüístico. En este campo se promueve un salto del signo lingüístico saussureano (significante/significado) al signo entendido desde una concepción triádica. En esta perspectiva, autores como Benveniste y Jakobson (o Pierce y Morris desde la semiótica), consignan que alguien dice algo a alguien sobre algo según una jerarquía de códigos presente en los distintos niveles del sistema lingüístico. La inclusión/exclusión del referente entraña una distinción notable: si es posible aglutinar el referente a su significado, o bien, existe una representación que media necesariamente entre ambos.

Según Barthes, esta fusión del referente y el significado en beneficio del primero posibilita el efecto de realidad en virtud del cual el referente, transformado de manera encubierta en significado estable, es revestido de un estatuto de verdad. En este sentido, Ricoeur destaca el planteamiento de Barthes respecto a que "la historia produce la ilusión de encontrar lo real que ella representa. En realidad, su discurso no es más que 'un discurso performativo falseado, en el que lo verificativo, lo descriptivo (aparente), no es, de hecho, más que el significante del acto de habla como acto de autoridad (...) la narración histórica muere porque el signo de la historia, de ahora en adelante, es no tanto lo real como lo inteligible'" (2010: 327). A la luz de lo expuesto, Ricoeur sostiene que es un intento vano querer establecer un vínculo directo entre la forma narrativa y los acontecimientos tal como se produjeron realmente: "ese vínculo sólo puede ser indirecto, a través de la explicación y, del lado de ésta, a través de la fase documental, la cual remite a su vez al testimonio y al crédito dado a la palabra de otro" (2010: 319). Así también, Achugar (2011) agrega que la construcción del discurso sobre el pasado implica un trabajo de selección de documentos, interpretación y comprensión/ explicación de eventos, participantes y circunstancias históricas concretas.

Si se trata de poner en el centro del debate el carácter narrativo en torno al cual se mueve la práctica historiográfica, conviene establecer una distinción en una dirección distinta. Ricoeur propone un corte epistemológico "entre las historias que se cuentan (stories) y la historia que se construye sobre las huellas documentales (history)" (2010: 315). Un planteamiento similar es proporcionado por el antropólogo Trouillot (1995), quien distingue en idénticos términos lo que él denomina 'los dos lados de la historicidad'. En sus palabras,

\begin{abstract}
Las personas participan en la historia como actores y como narradores. La ambivalencia inherente entre la palabra "historia" en muchas lenguas modernas, incluyendo el inglés, sugiere esta participación dual. En el uso vernáculo, la historia significa tanto los hechos en cuestión como las narrativas de esos hechos, tanto "lo sucedido" como "lo que se dice que ha pasado". El primer significado pone énfasis en los procesos socio-históricos, el segundo sobre nuestros conocimientos de esos procesos o sobre una historia acerca de esos procesos (1995: 2).
\end{abstract}

Trouillot afirma que la historia como proceso social involucra a individuos con tres capacidades distintas: 1) como agentes u 
ocupantes de posiciones estructurales; 2) como actores en constante relación con el contexto, y; 3) como sujetos, es decir, como voces conscientes de su enunciación. A los actores vincula un conjunto de capacidades que son específicas en el tiempo y el espacio en formas en que, tanto su existencia como su entendimiento, residen fundamentalmente sobre hechos históricos. Éstos, de acuerdo a Ricoeur (2010), son reales en cuanto se pueden documentar y testimoniar de manera verificable. Para Trouillot (1995), las narrativas históricas dirigen situaciones particulares $\mathrm{y}$, en este sentido, es primordial que las y los historiadores traten a los seres humanos a partir del horizonte analítico propuesto. Esta diversificación supone que el conocimiento histórico no sólo se construye sobre individuos, sino desde y con ellos.

A partir de la discusión esbozada, conviene interrogarse, entonces: "¿qué hace a algunas narrativas en lugar de otras lo suficientemente poderosas para pasar como historia aceptada y no historicidad en sí misma?" (Trouillot 1995: 6). Tanto Ricoeur como Trouillot ofrecen una respuesta atendiendo a un marco comunicativo. Son los grupos históricamente específicos quienes deciden si una narrativa particular pertenece a la historia (history) o a la ficción (story). Dicho de otro modo,

El binomio relato histórico/relato de ficción, tal como aparece ya constituido desde el punto de vista de los géneros literarios, es claramente un binomio antinómico. Una cosa es una novela, incluso realista, y otra un libro de historia. Se distinguen por el pacto implícito habido entre el escritor y su lector. Aunque no formulado, este pacto estructura expectativas diferentes por parte del lector y promesas diferentes en el autor (Ricoeur 2010: 342).
Atender esta propuesta pone de relieve no sólo el rol de las y los autores como productores de sentido de los discursos históricos, sino también el papel de los destinatarios que definen su incidencia y alcance. Se establece, entonces, un pacto de lectura donde los interlocutores operan diversas estrategias de análisis con el propósito de dar coherencia interpretativa y actualizar el relato en la experiencia inmediata. Así prevalecen ideas asociadas a la capacidad crítica de los interlocutores en tanto actores sociales, que ya no se limitan a leer la historia escrita por otros sobre otros, sino que se hacen parte activa de la misma.

De lo anterior se desprende que lograr esta acción, involucra repensar el rol de los sujetos en ella. En esta línea, Trouillot argumenta en contra de cierto 'fetichismo' por los hechos históricos, presupuesto sobre la extrapolación de modelos de comprensión de las ciencias naturales a las ciencias sociales. Esto refuerza la visión de que cualquier posicionamiento consciente debiese ser rechazado de antemano como ideológico. "Así, la posición del historiador es oficialmente no marcada: es la de un observador no histórico. Los efectos de esta postura pueden ser bastante irónicos, ya que las controversias históricas a menudo giran (...) sobre el posicionamiento del observador" (1995: 151). Por lo tanto, el llamado que subyace es a comprender críticamente la práctica historiográfica y a asumir los intereses que se ponen en juego, toda vez que los individuos no pueden disociarse de su carácter histórico intrínseco. En palabras de este autor, "nos acercamos a la era en que historiadores profesionales tendrán que posicionarse más claramente en el presente, no sea sólo que políticos, magnates o líderes étnicos escriban la historia por ellos" (1995: 152). 
En este contexto, acercarse a las formas de hacer historia supone cambiar de foco y echar luz sobre los procesos sociales que encarnan personas comunes, en tanto actores ineludiblemente involucrados en el devenir de su historia. Por ende, no es posible lograr una comprensión histórica sobre la premisa del traspaso de información objetiva, por cuanto cada discurso implica un proceso intelectual y emotivo, motivado por propósitos en el ámbito público o privado. La persecución de intereses sociales, políticos, económicos o culturales, movilizan explicaciones predominantes que pugnan por imponer y legitimar sus narrativas del pasado. Dicho de otro modo,

Existen múltiples maneras de manipular y acomodar la historia. Se suelen ocultar o acallar ciertos hechos y magnificar otros. Igualmente, se pueden mistificar determinadas acciones, focalizar la atención en algunos actores relegando voluntariamente al olvido a otros e introducir cortes de tiempo y periodificaciones hermenéuticas o políticas destinadas a descontextualizar ciertos hechos o procesos (Grez 2008: 179).

Un modo tradicional y hegemónico de comprender la naturaleza del conocimiento histórico, emana de una mirada desde arriba, en el sentido de que "siempre se ha centrado en las grandes hazañas de los grandes hombres" (Burke 2003: 17). A esta forma se opone cierto número de historiadores "conscientes de que su obra no reproduce 'lo que realmente ocurrió', sino que la presenta desde una perspectiva particular" (Burke 2003: 334). Éstos se interesan por "la "historia desde abajo', es decir, por las opiniones de la gente corriente y su experiencia del cambio social" (Burke 2003: 118); cuestión que supone "que la historia de la 'gente corriente' no puede divorciarse de la consideración más amplia de la estructura y el poder social" (Sharpe 2003: 51). En este sentido, Peter Burke señala que "La nueva historia es una historia escrita como reacción contra el paradigma tradicional (...) se ha supuesto que era la manera de hacer historia y no se consideraba una forma más de abordar el pasado entre otras varias posibles" (2003: 15). Este giro da cuenta de cómo se pone en crisis la noción de 'verdad histórica' $y$ se establece un paso significativo que considera la posibilidad de que otras voces se involucren en la narrativa social, conformando configuraciones ampliadas.

En este marco, Trouillot declara que "la conciencia temática sobre la historia no es activada sólo por reconocidos académicos. Somos todos historiadores aficionados con distintos grados de conciencia sobre nuestra producción" (1995: 20). Asimismo, Gabriel Salazar agrega que "cada sujeto popular e incluso cada ciudadano puede y debe ser su propio historiador, su propio científico social y su propio político" (2006: 159). En esta línea, se valora una 'historia desde dentro y desde abajo' capaz de restituir a ciertos grupos sociales la posibilidad de reconocerse identitariamente por medio de un pasado común, en la medida en que se nos recuerda "que nuestra identidad no ha sido formada simplemente por monarcas, primeros ministros y generales" (Sharpe 2003: 56). Según estos autores, resulta especialmente relevante demostrar que los miembros de las clases marginales son agentes cuyas acciones afectan decisivamente el mundo en que viven. Por lo tanto, subrayan la necesidad de darle un sentido a la experiencia de la gente corriente, y no únicamente para una reducida elite de personas instruidas y poderosas. De lo anterior se desprende que, 
en la epistemología de la ciencia y la gran política, la vida social termina a menudo convertida en un ideológico y por tanto maleable objeto de poder. Que no es lo mismo, ciertamente, que ser sujeto histórico. No cabe extrañarse, por eso, de que las Ciencias Sociales publiquen su producción cognitiva en textos teóricos de difícil traducción al lenguaje coloquial de la "vida", y que el Estado se rodee de textos escolares y legales, estadísticas nacionales y discursos oficiales donde difícilmente los ciudadanos corrientes de carne y hueso reconocerán los cruciales problemas "históricos" que deben arrostrar y resolver en su vida cotidiana. De este modo, producto de tal consanguinidad epistemológica, la Ciencia formal y el Estado sustentan su hegemonía sobre una "ciencia oficial" que es presentada, enseñada y controlada como si fuera la única ciencia legítima y verdadera (Salazar 2006: 143).

Este conjunto de relaciones desacreditan la idea fuertemente arraigada de que el pasado se corresponde con una realidad fija y una visión en torno al conocimiento histórico como contenidos inamovibles, naturales y estables. Para Trouillot, la historia no pertenece sólo a sus narradores, profesionales 0 aprendices. "Mientras algunos de nosotros debatimos qué es o fue la historia, otros la toman en sus propias manos" (1995: 153). En este sentido, es coherente la propuesta de Salazar en cuanto a que "la organización de la memoria y la experiencia populares no se ha producido, sin embargo, como un trabajo puramente intelectual o cultural, sino como parte de un movimiento más ancho de reagrupación social y reformulación identitaria" (2006: 150).

En efecto, diversos actores sociales con múltiples vínculos -personales y colectivos- a experiencias pasadas, aprenden, heredan y viven su propia historia, con el propósito de afirmar su legitimidad también como una versión posible. Ellas y ellos pretenden reivindicación respecto del discurso dominante, al tiempo que luchan por el poder o resisten a él, afirmando su continuidad o ruptura. De acuerdo a Jelin, "los agentes estatales tienen un papel y un peso central para establecer y elaborar la 'historia/memoria oficial'. Se torna necesario centrar la mirada sobre conflictos y disputas en la interpretación y sentido del pasado, y en el proceso por el cual algunos relatos logran desplazar a otros y convertirse en hegemónicos" (2001: 40). En palabras de Grez,

el conocimiento histórico es un ámbito donde también están presentes las luchas por la hegemonía y el poder. Resulta casi obvio afirmar que quienes impongan su visión del pasado tendrán mayores posibilidades de modelar los comportamientos del presente y diseñar las vías de desarrollo futuro. Por lo mismo, esta "capacidad operativa" del conocimiento histórico jugará su rol de distintas maneras según las circunstancias: a veces de manera directamente inducida, premeditadamente instrumental, como opera el saber en las "historias oficiales", pero en otras ocasiones, de manera más sutil porque el conocimiento "vulgar", esto es, el saber común sobre el pasado de una nación, un pueblo, una clase social o de cualquier grupo humano, inevitablemente, suele inspirar el sentido común de las personas, su vida colectiva, su ser social (...) Este conocimiento -atesorado a través del tiempo- se traduce en constitución de identidades, tradiciones y comportamientos colectivos e individuales, lo que no hace aventurado sostener que aquellos grupos carentes de una sólida memoria colectiva corren peligro de des-construirse, perder su fisonomía, diluir sus identidades en modelos propuestos por actores más fuertes y pujantes (2008: 81).

Lo anterior da luces respecto a que existe un modo más o menos normado de conocer el mundo, e ideológicamente dirigido al control de posiciones alternativas emergentes. Asimismo, los conocimientos que se naturalizan y se consensuan mediante la institucionalización de una serie de prácticas regulatorias, como 
la educación, por ejemplo, a partir de la elaboración de un discurso pedagógico de la historia (Oteíza 2006), afectan no sólo en la constitución identitaria de los individuos, sino en su capacidad de acción respecto de una serie de abusos y manipulaciones ejercidas en su vida diaria. Según Mudrovcic, "las acciones y experiencias pasadas adquieren sentido de acuerdo al 'lugar' que ocupan en el relato, otorgando, de este modo, coherencia a la vida presente del grupo. La narrativa histórica, debido a la completud de su estructura, provee, quizá, la representación del pasado más adecuada a la búsqueda presente de legitimación políticosocial de una comunidad dada" (2005: 96).

La discusión en torno a la articulación de prácticas que regulan el discurso histórico hasta otorgarle una posición dominante, se torna especialmente sensible al cuestionarnos sobre las acciones que estabilizan representaciones del pasado reciente, sobre todo si éste se ha conformado sobre la base de hechos traumáticos, como es el caso de las experiencias dictatoriales latinoamericanas ocurridas durante las últimas décadas, así como otras vivencias de vulneración a los derechos humanos ocurridas en Europa o Sudáfrica a mediados del siglo pasado. De acuerdo a Wodak:

\begin{abstract}
cada sociedad tiene que afrontar los hechos traumáticos de su pasado, ya sean guerras, torturas, asesinatos masivos, genocidio, violencia y violación a personas, entre otros similares. Con la frecuencia necesaria, existen tabúes que circundan dichos eventos en la esfera pública, o bien se construyen narrativas oficiales que mitigan, relativizan, niegan o mistifican la participación de ciertos grupos en crímenes de guerra o en otros crímenes (2011: 162).
\end{abstract}

En el mismo sentido, Achugar precisa que "a diferencia de otros periodos históricos, en el estudio del pasado reciente no se puede hacer una periodización a priori para saber qué casos incluir, ya que la cronología no es la categoría clave" (2011: 45). Según la autora, en este estudio predominan procesos traumáticos que se consideran disruptivos y generan discontinuidades a nivel individual y colectivo. De esta manera, al pensar el tiempo histórico en cuanto distintas categorías y procedimientos epistemológicos, es posible registrar experiencias a corto, mediano y largo plazo, que definen la conformación de la conciencia histórica de los grupos, la integración de sus experiencias y la comprensión intergeneracional de las mismas (Achugar 2011). Por esta razón, no puede traducirse el pasado, ni mucho menos el pasado reciente, a partir de una linealidad: su construcción responde a un proceso activo y dinámico que va más de allá de la mera reproducción de vivencias, sobre todo si éstas emergen de contextos traumáticos, en cuyos casos víctimas y victimarios aún viven. En cuanto a la transmisión de dichas experiencias y la conformación de la memoria social, Wodak añade que:

\begin{abstract}
en un gran número de países, muchos continúan exigiendo que se descarte la siguiente regla: ¿por qué seguir hablando de la historia y de narrativas sobre hechos que tuvieron lugar hace más de 50 años? Parece muy extraño, puesto que la historia se dedica a -sin ocuparse de los desacuerdoshechos, fuentes e interpretaciones que pueden tener más de miles de años. Esta renuencia ciertamente está vinculada con otros elementos de la historia contemporánea, quizás porque surgirían preguntas incómodas. Se rompería el silencio (2011: 164).
\end{abstract}

En este sentido, resulta imprescindible reflexionar sobre los procesos sociales que intervienen activamente en la construcción discursiva de representaciones históricas 
hegemónicas. De acuerdo a Wodak, siel pasado, reiterada y necesariamente, se entremezcla con el presente y el futuro, no es posible ni entender ni planificar el presente o el futuro sin tomar en consideración dicho pasado. Por lo tanto, se debe recalcar el interés académico por cuestionar y explicar de manera crítica cuáles son los aspectos decisivos y de qué manera influyen en los modos de representación de la experiencia reciente como discurso histórico legitimado. De allí que privilegiar una mirada que se aleje de los relatos monoglósicos, para situarse desde la polifonía y la valoración de voces anónimas diversas -sistemáticamente marginadas, ocultadas y negadas-, constituye un posicionamiento que asume un ejercicio político: "el combate por la historia (o por el saber histórico) es un combate político, ya que si bien la memoria colectiva de un pueblo no está constituida en lo fundamental por el saber "histórico científico" producido por los historiadores, no cabe duda que éste influye en la formación de identidades y tradiciones" (Grez 2008: 81).

En virtud del impacto social vinculado a ciertas formas de hacer historia, cabe concentrarse, específicamente, en los procesos de producción discursiva que las posibilitan. De acuerdo a Trouillot (1995) entre los extremos mecánicamente 'realistas' e ingenuamente 'constructivistas', se encuentra la más seria tarea de determinar ya no qué es la historia, sino cómo ésta trabaja. Se trata de develaciones históricas en sí mismas por medio de la producción de discursos específicos. Para este autor, "sólo enfocarnos sobre dicho proceso puede revelar los caminos en los cuales los dos lados de la historicidad se entrelazan en un contexto particular. Sólo por dicha superposición podemos descubrir el ejercicio diferencial de poder que hace a algunas narrativas posibles y silencia otras" (Trouillot 1995: 25). En este sentido, el discurso histórico, en su uso público, liga el pasado y el presente mediante la representación de los eventos y los sujetos involucrados en él. Dicho ejercicio contribuye a la configuración del sistema social al que pertenece, y constituye su punto de partida. En este sentido, el discurso -la narrativa histórica-, sirve de legitimación a cierta configuración de la realidad social y pone en relación inmediata los intereses personales e institucionales de una sociedad determinada. Con esto, se erige una red de referencias que "posibilitan la existencia de un pasado común, otorgándole integridad histórica" (Mudrovcic 2005: 90).

Tal como se ha discutido hasta aquí, sobre esta ideadepasadocomúnquepermitelaconstrucción identitaria y hace confluir acciones colectivas, reflexionan diversos autores que abogan por la posibilidad de relativizar los discursos históricos incluyendo otras voces, distintas de aquella oficial, homogénea y autorizada. En este punto, la práctica historiográfica se liga con la teoría literaria, considerando, por ejemplo, la noción de heteroglosia propuesta por Bajtín (1999), así como una serie de recursos retóricos y estilísticos destinados a la elaboración de la historia como relato. Hayden White (2003) en su obra El texto histórico como artefacto literario, señala que las versiones alternativas logradas $-y$, en cierto sentido, conflictivas y hasta mutuamente excluyentes-, son aceptadas como válidas y veraces ante sus audiencias, ya no por su correspondencia con los sucesos del pasado, sino por la manera en que ellas traman discursivamente dichos sucesos. En palabras de este autor, "la narrativa es más bien una distorsión del campo fáctico total al cual el discurso se propone representar" (2003: 21). 
En el ámbito de los estudios del discurso, Mariana Achugar (2011) se cuestiona en torno al papel del lenguaje en la construcción de representaciones sobre el pasado reciente. Según esta autora, las prácticas discursivas que colaboran en este proceso no son privativas del registro escrito, aun cuando la tendencia de la práctica historiográfica ha sido eminentemente escritural. El conocimiento histórico se reproduce, pues, en manuales de historia específicamente orientados a este propósito, así como en textos escolares que focalizan su enseñanza, pero también se comunica por medio de conmemoraciones, exposiciones, películas, documentales, conversaciones familiares, entre amigos, etc. Por lo tanto, investigar la incidencia del lenguaje en la conformación de narrativas históricas implica explorar: a) los significados del pasado y las negociaciones tendientes al consenso social mediante la predilección de orientaciones ideológicas específicas que organizan semióticamente dichas interpretaciones; b) las formas en cómo se distribuyen y reproducen ciertas versiones del pasado reciente, que tienen la capacidad de informar sobre el rol de la transmisión intergeneracional y su uso en la construcción de identidades políticas, institucionales y familiares. De esa manera,

un texto histórico no es sólo un conjunto de signos verbales que refieren una realidad extratextual, sino el resultado de (...) una 'actividad cooperativa', en virtud de la cual el historiador produce un cierto tipo de información que el lector debe actualizar dentro de un determinado contexto social. El destinatario del texto histórico constituye una parte del juego textual para el que se genera una estrategia discursiva específica con el objetivo de provocar una respuesta interpretativa determinada. Dentro de este proceso de comunicación el hecho de que un texto funcione como un texto de historia obedece, entonces, a ciertas convenciones sujetas al devenir histórico (...) El historiador (...) presupone un destinatario, lo que genera una estrategia textual específica (Mudrovcic 2005: 91-92).

En este marco, Ricoeur se plantea una pregunta relevante: "cómo, en qué medida el historiador satisface la expectativa y las promesas suscritas a ese pacto" (2010: 361). Para dar una respuesta, este autor establece una epistemología del conocimiento histórico, donde éste es el resultado de tres fases diferentes:

\begin{abstract}
llamo fase documental la que se efectúa desde la declaración de los testigos oculares a la constitución de los archivos y que se fija, como programa epistemológico, en el establecimiento de la prueba documental (...) Llamo después fase explicativa/comprensiva la que concierne a los usos múltiples del conector 'porque' que responde a la pregunta ‘ipor qué?': ¿por qué las cosas ocurrieron así y no de otra manera? (...) Llamo, finalmente, fase representativa a la configuración literaria o escrituraria donde se declara plenamente la intención historiadora, la de representar el pasado tal como se produjo -cualquiera que sea el sentido asignado a ese 'tal como'-. (2010: 177).
\end{abstract}

A partir de lo anterior, Burke consigna que "lo que los historiadores escriben actualmente son narrativas sobre narrativas" (2003: 328). En efecto, lo que Ricoeur propone como proceso específico de la práctica historiográfica, requiere de una documentación/testificación adecuada que sea antecedente para la fase escrituraria. Cabe preguntarse, entonces, ¿cuál es la memoria que se declara? Para Elizabeth Jelin,

Llevado al plano social, la existencia de archivos y centros de documentación, y aun el conocimiento y la información sobre el pasado, sus huellas en distintos tipos de soportes reconocidos, no garantizan su evocación. En la medida en que son activadas por el sujeto, en que son motorizadas 
en acciones orientadas a dar sentido al pasado, interpretándolo y trayéndolo al escenario del drama presente, esas evocaciones cobran centralidad en el proceso de interacción social (2001: 23).

En lo que respecta al entramado discursivo propiamente tal, Trouillot sostiene que el poder permea la historia (story) de modos diferentes y en distintos ángulos. Lo anterior "es pertinente incluso si podemos imaginarnos una historia totalmente científica, incluso si relegamos las preferencias de historiadores e intereses a una fase separada, post-descriptiva. En la historia, el poder comienza en la fuente" (1995: 29). De este modo, tanto lo que se considera como lo que se omite en las fuentes (artefactos y cuerpos que se convierten en un acontecimiento al interior del hecho), o en los archivos (hechos recopilados, tematizados y procesados como documentos y monumentos), implica un procedimiento que no es nunca neutral o natural. Se trata de documentaciones creadas, cuyas presencias y ausencias son más bien menciones o silencios de varias clases y grados. En este sentido, Le Goff agrega,

El documento no es inocuo. Es el resultado ante todo de un montaje, consciente o inconsciente, de la historia, de la época, de la sociedad que lo ha producido, pero también de las épocas ulteriores durante las cuales ha continuado viviendo, acaso olvidado, y ha continuado siendo manipulado, a pesar del silencio. El documento es una cosa que queda, que dura, y el testimonio, la enseñanza (apelando a su etimología) que aporta, deben ser en primer lugar analizados desmitificando el significado aparente de aquél. El documento es monumento. Él es resultado del esfuerzo cumplido por las sociedades históricas por imponer al futuro -queriéndolo o no queriéndolo- aquella imagen dada de sí mismas. En definitiva, no existe un documento-verdad. Todo documento es mentira. Corresponde al historiador no hacerse el ingenuo (2004: 238).
En este sentido, si la historia es aquella que se escribe, la memoria, en cambio, es aquella que se cuenta, que se transmite desde la oralidad, sin registro, al margen de los textos 'oficiales'. Para Ricoeur, "los documentos tenían su lector, el historiador entregado a su trabajo. El libro de historia tiene sus lectores, potencialmente cualquiera que sepa leer; de hecho, el público ilustrado. Al entrar en el espacio público, el libro de historia, coronación del 'hacer historia', reconduce al autor al corazón del 'hacer historia"' (2010: 307). De esta manera, el carácter escritural, especializado y específico de un público 'ilustrado' se conecta especialmente con otra distinción que Ricoeur establece en los términos de visibilidad/legibilidad.

En efecto, existe un vínculo urdido entre visibilidad y legibilidad desde el punto de vista de la recepción del texto histórico, y que asocio particularmente a un ejercicio de poder. Cuando algo es explicitado como representación, "asume simultáneamente las dos formas del relato, evocador de ausencia (...) [y] portador de presencia real” (Ricoeur 2010: 348). Para este autor, la legibilidad -que el discurso sea aprehensible en su estructura lingüística-, es lo que engendra visibilidad en el plano histórico. De acuerdo a Trouillot (1995), esta relación da cuenta de las múltiples maneras en que las producciones de narraciones históricas involucran una contribución irregular de parte de los individuos o grupos que compiten por imponer sus visiones del pasado; lo anterior promueve, necesariamente, un acceso desigual a los significados de dichas producciones.

A este respecto, Ricoeur introduce la noción de ideología. De ella aclara que "tiene lugar precisamente en el resquicio entre el requerimiento de legitimidad que emana de 
un sistema de autoridad y nuestra respuesta en términos de creencia" (2010: 113). De este modo, la ideología ingresa en el ámbito de las mediaciones simbólicas, en que la memoria es incorporada a la constitución de la experiencia social a través de la función narrativa. Es, precisamente, la configuración discursiva que da forma a la historia narrada, lo que contribuye a modelar la identidad de los sujetos históricos, así como los contornos de su propia acción. Asimismo, la función selectiva del discurso histórico ofrece la ocasión y los medios para llevar a cabo una estrategia que conjuga memoria y olvido, tal como se profundizará a continuación. En palabras de Ricoeur,

los recursos de manipulación que ofrece el relato se hallan movilizados fundamentalmente en el plano en el que la ideología actúa como discurso justificativo del poder, de la dominación (...) El relato impuesto se convierte así en el instrumento privilegiado de esta doble operación. La plusvalía que la ideología añade al crédito ofrecido por los gobernados para responder a la reivindicación de legitimación suscitada por los gobernantes, presenta también una textura narrativa: relatos de fundación, relatos de gloria y humillación alimentan el discurso de la adulación y del miedo. De este modo, se hace posible vincular los abusos expresos de la memoria a los efectos de distorsión propios del plano del fenómeno de la ideología. En este plano aparente, la memoria impuesta está equipada por una historia 'autorizada', la historia oficial, la historia aprendida y celebrada públicamente. Una memoria ejercitada, en efecto, es, en el plano institucional, una memoria enseñada; la memorización forzada se halla así enrolada en beneficio de la rememoración de las peripecias de la historia común, consideras como los acontecimientos fundadores de la identidad común (2010: 115-116).

\section{Sobre la memoria, el silencio y el olvido}

El texto memorial surge como una forma de resistencia a la narrativa histórica oficial, única y verdadera; la memoria está para desafiar el discurso hegemónico y enriquecer la narrativa social. Según Le Goff (2004) la memoria colectiva ha constituido un hito importante en la lucha por el poder conducida por las fuerzas sociales. Asimismo, apoderarse de la memoria y del olvido es una de las máximas preocupaciones de los individuos y los grupos que han dominado y dominan las sociedades históricas. En este proceso las omisiones, los olvidos, los silencios de la historia son reveladores de estos mecanismos de manipulación de la memoria colectiva.

Las luchas de la memoria, por tanto, son también las luchas por el poder desde el cual legitimar la experiencia. Lo que vuelve conflictiva la convivencia de narrativas históricas disímiles no es tanto la naturaleza de las mismas como la función social que desempeñan. La pugna se genera desde el momento en que se concibe la necesidad de perpetuar determinado orden social, en virtud del posicionamiento de algunas narrativas por sobre otras. De esta manera, tanto el Estado como los ciudadanos corrientes ocupan el olvido y la memoria para validar sus historias, ya sea imponiéndolas, ya sea resistiendo a partir de ellas. Por un lado, tenemos que:

Hay una cierta forma de hacer la historia como relato institucional. Se la construye entonces como discurso de los 'dueños' del presente, para articularla con un pasado que afianza su visión y organización del mundo. Este relato histórico trata de explicar y organizar los eventos estructurándolos como procesos que obedecen a causas precisas y que a su vez generan otros fenómenos, que 
incluso pueden entrar en crisis, pero siempre bajo la mirada tranquilizadora de la racionalidad vigente, que organiza la generalización, la comprensión y la explicación de los grandes procesos. En último término, esta historia, como relato que convalida las relaciones de poder actuantes, pretende el control de su pasado y, simétricamente, del presente y el futuro (Calveiro 2008: 63).

No obstante lo anterior, resulta engañoso pensar que sólo sea posible aquella historia que se visibiliza, aunque ésta sea la pretensión del Estado, que procura incansablemente por medio de sus mecanismos materiales y simbólicos de represión. Existe no una, sino diversas memorias que conviven al margen de la historia oficial, y que encarnan la rememoración colectiva de las personas comunes. Los sujetos que libran esta batalla de la memoria (Illanes 2002) proyectan sus luchas en el terreno social, sirviéndose de distintas formas de mediación comunicativa. Según Jelin, "la memoria tiene entonces un papel altamente significativo, como mecanismo cultural para fortalecer el sentido de pertenencia a grupos o comunidades. Amenudo, especialmente en el caso de grupos oprimidos, silenciados y discriminados, la referencia a un pasado común permite construir sentimientos de autovaloración y mayor confianza en uno/a mismo/a y en el grupo" (2001: 10).

Por consiguiente, es posible sostener que las memorias no están determinadas única y mecánicamente por hechos históricos objetivos, sino que se encuentran mediadas por ideologías que selectivamente resaltan ciertos sucesos y actores, volviéndolos relevantes en un contexto social particular. Las ideologías son producidas y reproducidas en los discursos (van Dijk 1999), por lo que es posible acceder a diversas representaciones ideológicas acerca del pasado, especialmente a aquellas que están presentes en los discursos de las elites simbólicas (históricos, políticos, medios de comunicación y libros de texto, entre otros). A partir del control que ejercen estos discursos, se puede establecer, en algún sentido, cuáles son las memorias que compartimos como miembros de diferentes grupos sociales y qué tipos de construcciones identitarias son proyectadas por éstas en el momento presente.

Al atender el planteamiento de Ricoeur sobre una pragmática de la memoria, cabe señalar que su ejercicio está vinculado con cierto uso transformado en acción. No obstante, este uso implica siempre la posibilidad de abuso. De acuerdo al autor, éstos "se derivan de la manipulación concertada de la memoria y del olvido por quienes tienen el poder" (2010: 110). Quienes manipulan lo hacen mediante los efectos de "distorsión de la realidad, de legitimación del sistema de poder, de integración del mundo común por medio de sistemas simbólicos inmanentes a la acción" (2010: 112). Desde esta perspectiva, Jelin afirma que el olvido y el silencio ocupan un lugar central. Dado que toda narrativa del pasado implica una selección, la memoria total se vuelve imposible. De allí que varios autores coincidan en que existe cierto olvido 'necesario' para la sobrevivencia y el funcionamiento del sujeto individual y de los grupos y comunidades, dado que hay aspectos de la vida en sociedad que deben ir quedando al margen para que emerjan otros de distinto valor. Lo que interesa destacar en este punto es "la multiplicidad de situaciones en las cuales se manifiestan olvidos y silencios, con diversos 'usos' y sentidos” (Jelin 2001: 29).

A la luz de estos contextos se olvida en dos sentidos diferentes: mediante la ausencia intencionada de los recuerdos de sujetos 
comunes que ejecutan quienes controlan la historia oficial, pero también olvidan los ciudadanos corrientes que se disponen a abandonar el miedo y la parálisis que impone el terrorismo de Estado (Obando 2008; Calveiro 2008). Es así como utilizar el olvido a favor o no de la memoria, puede también delimitar su poder como elemento de lucha o destrucción social. Para Ricoeur, existe un olvido definitivo por medio de la destrucción de huellas, así como un olvido reversible que "designa el carácter desapercibido de la perseverancia del recuerdo, su sustracción a la vigilancia de la conciencia" (2010: 563). Es, justamente, este último olvido el que constituye la base para la invisibilización de determinados actores sociales y de sus experiencias históricas, sobre todo en contextos traumáticos cuyo reconocimiento es necesariamente controversial y polémico. El olvido es reversible precisamente porque los sujetos históricos persisten y es posible su percepción si se desafía la clausura de las memorias colectivas.

En conexión con lo anterior, Trouillot define la noción de 'silencio' como "un proceso activo y transitivo: uno 'hace callar' un hecho o un individuo como un silenciador hace callar un arma" (1995: 48). En este sentido, aclara Achugar, "la memoria necesita ser autorizada por otro" (2011: 63). En cuanto al uso del silencio, Trouillot clarifica que éste forma parte de los procesos de producción histórica en cuatro momentos cruciales: en la creación de hechos y fuentes de las que se extraen; cuando se conectan los hechos a partir de la creación de archivos; cuando se recuperan los hechos mediante la configuración narrativa, y; cuando se realiza un retrospección significante, es decir, cuando se constituye la history en su etapa final. Por lo tanto, se hace posible afirmar que "cualquier narrativa histórica es un conjunto particular de silencios, el resultado de un proceso único, y la operación requerida para deconstruir estos silencios variarán como corresponda" (1995: 27). En este sentido, hacer reversible el olvido reservado o generar una deconstrucción de los silencios, implica considerar que:

Todo lo que constituye la fragilidad de la identidad aparece como ocasión de manipulación de la memoria, principalmente por vía ideológica. ¿Por qué los abusos de la memoria son de entrada abusos del olvido? Lo habíamos dicho entonces: precisamente por la función mediadora del relato, los abusos de memoria se hacen abusos de olvido (...) Como decíamos entonces, fue posible la ideologización de la memoria gracias a los recursos de variación que ofrece el trabajo de configuración narrativa (...) Para quien atravesó todas las secciones de configuración y de refiguración narrativa, desde la constitución de la identidad personal hasta la de las identidades comunitarias que estructuran nuestros vínculos de pertenencia, el peligro principal, al término del recorrido, está en el manejo de la historia autorizada, impuesta, celebrada, conmemorada -de la historia oficial-. El recurso al relato se convierte así en trampa, cuando poderes superiores toman la dirección de la configuración de esta trama e imponen un relato canónico mediante la intimidación o la seducción, el miedo o el halago. Se utiliza aquí una forma ladina de olvido, que proviene de desposeer a los actores sociales de su poder originario de narrarse a sí mismos (Ricoeur 2010: 572-573, cursiva mía).

Dicho poder, en el marco de coyunturas históricas traumáticas, fue negado $y$ desterrado de las comunidades vulneradas. En Latinoamérica y Chile, al finalizarse los periodos dictatoriales, se tomaron medidas institucionales orientadas al perdón y la reconciliación nacional, a manos de los gobiernos a cargo de llevar adelante las transiciones democráticas. Entre las principales determinaciones tomadas, se constituyeron 
grupos de investigación que arrojaron informes sobre la violación a los derechos humanos, se pusieron en marcha procesos judiciales para determinar la responsabilidad de militares y funcionarios públicos involucrados en dichos vejámenes, y se promulgaron leyes tendientes a dar protección a las víctimas de prisión política, así como a sus familiares directos. No obstante, aun en la actualidad permanece la interrogante acerca del destino que tuvieron miles de detenidos desaparecidos, así como un pacto que asegura impunidad quebrantando el derecho a la verdad y la justicia a los ciudadanos violentados, y consecutivamente, olvidados y silenciados.

\section{Palabras finales: algunas reflexiones sobre la reconstrucción de la memoria traumática y la enseñanza del pasado reciente}

Como corolario de esta exposición preciso, por un lado, algunos planteamientos en torno a cómo se negocian significados sobre el pasado reciente a fin de reconstruir la memoria traumática y, por otro lado, vinculo esta práctica con la necesidad de pensar en una pedagogía crítica que enfatice la enseñanza del lenguaje en uso como medio para la comprensión y la reflexión histórica. En este sentido, planteo una interrogante que enlaza ambas direcciones propuestas: ¿dónde se aprende la historia?

Según Achugar, dicho aprendizaje se realiza en diversos contextos que no corresponden, necesaria ni exclusivamente, al aula: "el conocimiento histórico se desarrolla como una compleja relación/interacción entre experiencias en el hogar, la comunidad, la escuela y la cultura popular" (2011: 44). Por ende, se articulan complejas relaciones semióticas que intervienen en la adquisición del conocimiento histórico y su reproducción. Dicho vínculo se experimenta fundamentalmente como una práctica comunicativa, toda vez que la negociación y la transformación de la memoria sobreviene a partir de usos discursivos específicos. Tales usos se instancian mediante la transmisión intergeneracional, esto quiere decir que "distintas generaciones recuerdan los mismos eventos y sus personajes de forma distinta" (Achugar 2011: 79). Por ejemplo, en conversaciones familiares, se recontextualizan las memorias de generaciones anteriores (participantes directos) para alinearse con posiciones moralmente correctas en la actualidad. Por lo tanto, los relatos sobre el pasado reciente sirven como modelos culturales con los que interpretar la experiencia traumática. Lo que sucede, entonces, es que la generación mayor encuentra significados inmediatos, mientras que la nueva generación reinterpreta dicho significado para integrarlo a su propia vivencia.

De lo anterior se desprende la importancia que adquiere el derecho a la rememorización, tanto en la esfera privada como pública. De esta manera, "el recordar para la familia implica mantener los lazos de solidaridad; en cambio para la institución es validar su autoridad y su hegemonía sobre las narraciones posibles" (Achugar 2011: 81). En esta dirección, los grupos construyen cierta solidaridad ideológica que permite mantener relaciones estables y definir sus identidades y acciones. Es así como los discursos sobre la historia reciente ayudan a conectar de manera coherente la historia personal (autobiográfica) y la historia nacional, de modo que se coordinan o interpretan una en función de la otra (Achugar 2011). De acuerdo a esta autora, la memoria es un conocimiento 
distribuido socialmente; la memoria individual es apoyada por la de otros a través de estrategias epistémicas que validan y autorizan la propia. En esta línea, la modificación de la memoria se produce en etapas; en el caso de la memoria traumática, primero se genera una grieta que luego es reparada, aunque siempre recurriendo a narrativas esquemáticas (modelos) para organizarlas. En virtud de esta descripción conviene preguntarse, entonces, ¿cuál es el papel de la enseñanza en dicho modelamiento?

A mi juicio, una pedagogía orientada críticamente debiese tender a la formación de la conciencia histórica justamente en las generaciones más jóvenes, pues son ellas quienes determinan cómo se recuerda el pasado traumático (se haya experimentado 0 no directamente). Achugar añade a este respecto que "la posibilidad de conectar conocimiento histórico y decisiones éticas en el presente requiere de un trabajo de la persona/grupo que usa el discurso sobre el pasado" (2011: 81). Por ello se torna fundamental una enseñanza acerca de cómo funciona el lenguaje en contextos específicos para poder llevar a cabo dicha síntesis, pues narrar la historia reciente implica tomar decisiones tanto a nivel de qué pasó, como de qué significa aquello que ocurrió y qué implica comunicarlo. De allí que el aprendizaje sobre el pasado esté textualmente mediado, lo que vuelve prioritario indagar sobre el papel del discurso en las prácticas sociales.

En concordancia con lo anterior, Achugar recalca la necesidad de explorar el posicionamiento intertextual y dialógico para integrar la circulación y la recepción de textos dentro de los procesos de enseñanza. Asimismo, J. R. Martin (2011) precisa una serie de acciones que ejecutar al interior de las aulas como, por ejemplo: a) analizar la influencia que los textos escolares de historia ejercen en la ideología de los estudiantes, sobre todo cuando a la mayoría de ellos no se les enseña a leerlos críticamente; b) incentivar en los alumnos formas de leer y escribir a través del discurso en el aula, de un modo que los prepare para una ciudadanía productiva y les provea el andamiaje necesario para ascender/descender en las nociones disciplinares requeridas, y; c) capacitar a los docentes a llevar un ciclo de enseñanza/ aprendizaje que incluya una fase de modelado (señalar el género del discurso en cuestión, así como su propósito social, etapas y rasgos lingüísticos) y de construcción conjunta (realizar una escritura interactiva de un segundo modelo basado en las sugerencias de los estudiantes).

En este sentido, desde los estudios del discurso y la lingüística crítica, se ha desarrollado una productiva línea de investigación que ha puesto especial énfasis en la adquisición de un metalenguaje que permita acceder a los textos que colaboran en la construcción de conocimientos históricos, a partir de los distintos efectos de sentido que proveen sus configuraciones semióticas. Sólo por mencionar algunos casos, diversas experiencias que han relevado la historia reciente de países tales como Estados Unidos (Schiffrin 2001), Australia (Coffin 2003; Martin 2008), Austria (Wodak 2006), España (Pinto 2004, 2011; Atienza 2007, 2011), Argentina (Bietti 2009; Giudice y Moyano 2010), Colombia (Barletta y Mizuno 2010; Chamorro y Moss 2010), Uruguay (Achugar, Fernández y Morales 2011) y Chile (Oteíza 2003, 2006, 2009, 2011) entre otros, dan cuenta de estudios centrados en la reconstrucción de la memoria traumática en contextos públicos de enseñanza no formal, así como de instrucción regulada de la historia reciente en las aulas. 
En todos ellos, el denominador común radica en proveer herramientas de análisis que consideren usos y contextos, de manera tal de precisar el funcionamiento de múltiples estrategias sistemáticas que validan la reproducción de discursos que transmiten la 'historia oficial', autorizada y legitimada, tras coyunturas históricas polémicas, como ocurre con experiencias de exterminio, violación a los derechos humanos, desapariciones o asesinatos. Lo anterior, con el firme propósito de incentivar la adquisición de una conciencia crítica del lenguaje orientada a la deconstrucción ideológica de dichos mensajes, atendiendo la necesidad de ampliar los marcos interpretativos para la comprensión ciudadana, la recuperación del pasado reciente, junto con sus quiebres y heridas, a fin de resistir la manipulación de los acontecimientos efectivos a favor de lecturas hegemónicas que niegan el derecho a la memoria, ocultando y marginando el recuerdo de las generaciones actuales. Todo lo anterior, se cumple en tanto:

transmitir el pasado discursivamente requiere de un trabajo y esfuerzo por construir significados por parte del que lo transmite así como de quien lo recibe. El construir una identidad histórica le permite a una persona concebirse como parte de un grupo que relaciona el tiempo a su experiencia de vida con el tiempo de la historia de otros. Es esta intersección entre el tiempo personal y el tiempo del grupo lo que nos hace darnos cuenta de nuestra historicidad (Achugar 2011: 82).

\section{Bibliografía}

Achugar, M. 2011. "Aproximaciones discursivas a la transmisión del pasado reciente: síntesis cualitativa". En (re)construcción: discurso, identidad y nación en los manuales escolares de historia y de ciencias sociales. Oteíza, T.; Pinto, D. (Eds.) Santiago: Cuarto propio. 43-88.

Fernández, A.; Morales, N. 2011. "(Re)presentado el pasado reciente: la última dictadura uruguaya en los manuales de historia". Discurso y Sociedad 5, 2: 196-229.

Atienza, E. 2007. "Discurso e ideología en los libros de texto de ciencias sociales". Discurso y Sociedad 1, 4: 543-574.

2011. "La construcción de las identidades colectivas en libros de Ciencias Sociales en España". En (re)construcción: discurso, identidad y nación en los manuales escolares de historia y de ciencias sociales. Oteíza, T.; Pinto, D. (Eds.) Santiago: Cuarto propio. 321-348.

Bajtín, M. 1999. Estética de la creación verbal. México: Siglo XXI.

Barletta, N.; Mizuno, J. 2011. "Una propuesta metodológica para la meta-reconstrucción de la realidad histórica". En (re)construcción: discurso, identidad y nación en los manuales escolares de historia y de ciencias sociales. Oteíza, T.; Pinto, D. (Eds.) Santiago: Cuarto propio. 89-128.

Bietti, L. 2009. "Entre la cognición política y la cognición social: el discurso de la memoria colectiva en Argentina". Discurso y Sociedad 3, 1: 44-89.
Burke, P. 1996. Hablar y callar. Funciones sociales del lenguaje a través de la historia. Gedisa: Barcelona. 2003. Formas de hacer historia. Madrid: Alianza Editorial.

Cabruja, T.; Iñiguez, L.; Vásquez, F. 2000. "Cómo construimos el mundo: relativismo, espacios de relación y narratividad". Anàlisi 25: 61-94.

Calveiro, P. 2008. "La memoria como futuro". Actuel Marx Intervenciones 6: 59-74.

Coffin, C. 2003. "Reconstruals of the past-settlement or invation? The rol of JUDGEMENT analysis". Re/Reading the past. Critical and functional perspectives on time and value. Martin, J. R.; Wodak, R. (Eds.). Amsterdam: John Benjamins Publishing Company. 219-246.

Chamorro, D.; Moss, G. 2011. "La pedagogía de la simplificación: el estudio de la historia por medio de la pista y pesca". En (re)construcción: discurso, identidad y nación en los manuales escolares de historia y de ciencias sociales. Oteíza, T., Pinto, D. (Eds.) Santiago: Cuarto propio. 269-320.

Giudice, J.; Moyano, E. 2011. "Género y formación de ciudadanos: la re-construcción del período 1976-1983 en manuales argentinos para la escuela primaria". En (re)construcción: discurso, identidad y nación en los manuales escolares de historia y de ciencias sociales. Oteíza, T.; Pinto, D. (Eds.) Santiago: Cuarto propio. 205-268. 
Gramsci, A. 1968. Cultura y literatura. Barcelona: Ediciones Península.

Grez, S. 2008. "Historiografía y memoria en Chile. Algunas consideraciones a partir del Manifiesto de historiadores". HAOL 16 : 179-183.

Habermas, J. 2001. Teoría de la acción comunicativa: complementos y estudios previos. Madrid: Cátedra. Illanes, M. 2002. La batalla de la memoria. Santiago: Planeta. Jelin, E. 2001. Los trabajos de la memoria. Madrid: Siglo XXI Editores.

Lechner, N. 2006. Las sombras del mañana. La dimensión subjetiva de la política. Santiago: LOM.

Le Goff, J. 2004. El orden de la memoria. Barcelona: Paidós.

Lotman, I. 1998. Semiótica de la cultura, del texto, de la conducta y del espacio. Madrid: Cátedra.

Martin, J. R. 2008. "Intermodal reconciliation: Mates in Arms". New literacies and the English Curriculum: Perspectives. Unsworth, L. (Ed.). London: Continuum. 112-148.

2011. "Prólogo". En (re)construcción: discurso, identidad y nación en los manuales escolares de historia y de ciencias sociales. Oteíza, T.; Pinto, D. (Eds.) Santiago: Cuarto propio. 11-17.

Mudrovcic, I. 2005. Historia, narración y memoria. Los debates actuales en filosofía de la historia. Madrid: Akal.

Obando, A. 2008. "El (ab)uso del olvido. Terrorismo de Estado y lesión a la memoria colectiva". Actuel Marx Intervenciones 6: 75-86.

Oteíza, T. 2003. "How contemporary history is presented in chilean middle school textbooks". Discourse \& Society 14, 5: 639660.

2006. El discurso pedagógico de la historia. Un análisis lingüístico sobre la construcción ideológica de la historia de Chile. Santiago: Frasis

2009. "Diálogo entre textos e imágenes: análisis multimodal de textos escolares desde una perspectiva intertextual". Delta 25: 657-664.
2011. "Representación de las memorias del pasado: intersubjetividad en el discurso pedagógico de la historia". En (re)construcción: discurso, identidad y nación en los manuales escolares de historia y de ciencias sociales. Oteíza, T.; Pinto, D. (Eds.) Santiago: Cuarto propio. 129-172.

Pinto, D. 2004. "Indoctrinating the youth of past-war Spain: A discourse analysis of a fascist civics textbook". Discourse \& Society 15, 5: 649-667.

2011. "La cortesía y la formación del espíritu nacional en los libros escolares franquistas". En (re)construcción discurso, identidad y nación en los manuales escolares de historia y de ciencias sociales. Oteíza, T.; Pinto, D. (Eds.). Santiago: Cuarto Propio. 173-204.

Potter, J. 1998. La representación de la realidad. Discurso, retórica y construcción social. Barcelona: Paidós.

Ricoeur, P. 2010. La memoria, la historia, el olvido. Buenos Aires: Fondo de Cultura Económica.

Salazar, G. 2006. "La historia como ciencia popular: Despertando a los "Weupifes"'. Revista Austral de Ciencias Sociales 11: 143-168.

Schiffrin, D. 2001. "Language and public memorial: 'America's concentration camps'. Discourse \& Society 12, 4: 505-543.

Sharpe, J. 2005. "Historia desde abajo". Formas de hacer historia. Burke, P. (Ed.). Madrid: Alianza Editorial. 38-58.

Trouillot, M. R. 1995. Silencing the past: power and the production of history. Boston: Beacon Press.

Van Dijk, T. 1999. Ideología. Una aproximación multidisciplinaria. Barcelona: Gedisa.

2009. Discurso y poder. Barcelona: Gedisa.

White, H. 2003. El texto histórico como artefacto literario. Barcelona: Paidós.

Wodak, R. 2011. "La historia en construcción/La construcción de la historia. La "Wehrmacht alemana" en los recuerdos colectivos e individuales de Austria". Traducción de Euclides Palacios. Discurso y Sociedad 5, 1: 160-195. 
